\title{
Health and Welfare Outcomes for Adolescents Following Release from Prison in Queensland, Australia: A Prospective Cohort Study
}

\author{
Rohan Borschmann ${ }^{1,2,3,4, * \mathbb{D}}$, Dominique de Andrade ${ }^{5,6,7}$ and Stuart A. Kinner 1,2,7,8,9 \\ 1 Justice Health Unit, Centre for Health Equity, Melbourne School of Population and Global Health, \\ University of Melbourne, 207 Bouverie Street, Parkville 3010, Australia; s.kinner@unimelb.edu.au \\ 2 Centre for Adolescent Health, Murdoch Children's Research Institute, Royal Children's Hospital, \\ 50 Flemington Road, Parkville 3052, Australia \\ 3 Health Service and Population Research Department, Institute of Psychiatry, Psychology \& Neuroscience, \\ King's College London, David Goldberg Building, De Crespigny Park, Denmark Hill, London SE5 8AF, UK \\ 4 Melbourne School of Psychological Sciences, University of Melbourne, Parkville 3010, Australia \\ 5 Centre for Drug Use, Addictive and Anti-Social Behaviour Research, School of Psychology, Deakin University, \\ 221 Burwood Highway, Waurn Ponds 3125, Australia; d.deandrade@deakin.edu.au \\ 6 Lives Lived Well Research Group, School of Psychology, University of Queensland, Brisbane, \\ Sir Fred Schonell Drive, St. Lucia 4067, Australia \\ 7 Griffith Criminology Institute, Griffith University, Messines Ridge Road, Mt. Gravatt 4122, Australia \\ 8 Mater Research Institute-UQ, University of Queensland, Level 3, Aubigny Place, Raymond Terrace, \\ South Brisbane 4101, Australia \\ 9 School of Public Health and Preventive Medicine, Monash University, Melbourne 3800, Australia \\ * Correspondence: rohan.borschmann@unimelb.edu.au
}

Citation: Borschmann, R.; de Andrade, D.; Kinner, S.A. Health and Welfare Outcomes for Adolescents Following Release from Prison in Queensland, Australia: A Prospective Cohort Study. Adolescents 2021, 1 , 175-185. https://doi.org/10.3390/ adolescents1020014

Academic Editor: Emma Sorbring

Received: 30 March 2021

Accepted: 7 May 2021

Published: 12 May 2021

Publisher's Note: MDPI stays neutral with regard to jurisdictional claims in published maps and institutional affiliations.

Copyright: (c) 2021 by the authors. Licensee MDPI, Basel, Switzerland. This article is an open access article distributed under the terms and conditions of the Creative Commons Attribution (CC BY) license (https:// creativecommons.org/licenses/by/ $4.0 /)$.
Abstract: Background: The transition from prison to the community can be a difficult process and may present different challenges for adolescents (aged $<25$ years) compared with their older peers. Methods: Using data from a prospective cohort study in Australia, we compared the health and welfare outcomes of adolescents (aged $<25$ years) and adults (aged $\geq 25$ years) at 1,3 , and 6 months after release from prison. Results: After one month, adolescents were less likely to be unemployed (adjusted odds ratio (aOR) 0.31; 95\% CI 0.15-0.63), report low levels of social support (aOR 0.41; 95\% CI 0.21-0.80), or report high psychological distress (aOR 0.50; 95\% CI 0.25-0.99). After three months, adults were more likely to have visited a general practitioner (aOR 2.05; 95\% CI 1.04-4.07) and adolescents remained less likely to be unemployed (aOR 0.37; 95\% CI 0.19-0.74). After six months, adolescents were three times more likely to have used amphetamine-type stimulants (aOR 3.42; 95\% CI 1.29-9.09). Conclusions: Adolescents experience different challenges than their older peers when transitioning from prison to the community. Age-specific, integrated support is needed for adolescents during this critical period, including strategies to promote early primary care contact, capitalise on social support networks, and discourage risky substance use.

Keywords: transition; incarceration; adolescence; young adulthood; substance use; primary care

\section{Introduction}

Adolescents (defined as those aged $<25$ years [1,2]) who experience incarceration are, in many ways, the archetypal group of vulnerable young people, often having life trajectories characterised by multiple disadvantages, instability, abuse and neglect [1-4]. Overrepresented in prisons in many high-income countries, including Australia [5], incarcerated adolescents report higher rates of health-compromising behaviours, such as smoking, injection drug use and harmful alcohol use, both prior to [6,7] and during [8] incarceration, compared with their older peers. They also report poorer educational attainment and lower rates of employment prior to incarceration [6]. Despite this, little is known about the health and welfare outcomes of adolescents following release from prison. 
The transition to the community following release from prison can be a challenging process [9]. For many people, release from custody compounds pre-existing social disadvantages as they seek to secure accommodation and income, gain access to health services, and reintegrate into families and communities [10-12]. To date, there is almost no evidence documenting how this transition is experienced by vulnerable adolescents who, if they were in the community, would be recognised as having age-specific support needs. Additionally, although adolescents in youth detention are, by definition, considered 'youth' with unique and age-specific needs, the age-specific and developmental needs of adolescents in adult prisons are less recognised $[6,9,13,14]$. Furthermore, it is not known whether age-related differences in the aforementioned health risk behaviours exist after release from incarceration, and a detailed profile of post-release psychosocial and behavioural outcomes in adolescents compared with their older peers has not been documented. This information could inform the development of adolescent-targeted health promotion and prevention strategies prior to, during, and after incarceration.

While some cross-sectional studies of people in prison have stratified by age [6,9], very few studies have considered whether health and welfare outcomes after release from prison differ between adolescents and their older peers. One exception is a 2013 study by van Dooren and colleagues [15], which found that the elevation in risk of death after release from prison (compared with age- and sex-matched community peers) was greater in adolescents (aged $<25$ years) than in their older peers. Using data from the Passports study, a randomised controlled trial of a case management intervention for people transitioning from prison to the community in Queensland, Australia [16-18], the aim of this study was to address this gap in the literature by examining whether health and welfare outcomes differ between adolescents and their older peers in the first six months after release from prison.

\section{Method}

\subsection{Participants}

The cohort consisted of 1325 sentenced males $(1047 ; 79 \%)$ and females $(278 ; 21 \%)$, recruited from seven prisons in Queensland, Australia between August 2008 and July 2010. A total of 337 participants (25\%) were aged under 25 years, including 269 males $(80 \%)$ and 68 females $(20 \%)$. Participants were expected to be released from custody within six weeks of their baseline interview date and provided informed, written consent prior to participation. Based on assessed demographic and criminal justice variables, the cohort was broadly representative of people released from Queensland prisons during the study period [18], with the exception that women were deliberately oversampled to permit sex-stratified analyses. A detailed description of the recruitment process is provided elsewhere [18].

\subsection{Data Sources}

Data were originally collected for the Passports study, a randomised controlled trial of a service brokerage intervention designed to increase presentation to health care services after release from prison [16-18]. Baseline interviews covered socio-demographic and socioeconomic characteristics, physical and mental health, health-related risk behaviours, quality of life, intellectual disability, substance use, social support and transitional arrangements. Further data on HIV, hepatitis B and hepatitis C infection, and medication use were extracted from prison medical records with participant consent. Follow-up telephone interviews at 1, 3 and 6 months post-release were conducted in the community and repeated the measurement of most baseline variables. Participants who were re-incarcerated at the time of follow-up were interviewed in prison (either by telephone or face-to-face); however, these data were excluded from the analyses presented here in light of the focus on postrelease experiences in the community. The number of participants interviewed in prison during follow-up (and thus excluded from our analyses on this basis) was as follows: 1 month follow-up $(n=45) ; 3$ month follow-up $(n=104)$; and 6 month follow-up $(n=209)$. 


\subsection{Measures}

\subsubsection{Exposure Variable}

Our exposure variable was participant age at the time of the baseline interview. Consistent with the United Nations' definition of a young person [2], age was recoded as a dichotomous variable ( $<25$ years vs. $\geq 25$ years) for all analyses, with the reference category being $\geq 25$ years of age.

\subsubsection{Outcome Variables}

Based on a review of the literature, we selected 14 outcomes that were indicators of health or welfare-related risk behaviours, reported at 1, 3 and 6 month follow-up interviews. All outcome variables were dichotomised and were measured by self-report unless otherwise specified.

There were eight primary outcomes that focused on health-related behaviours. 'Unsafe sex' was defined as penetrative sex with at least one casual partner since the previous interview, without a condom. The number of primary care contacts since the last interview was collected by self-report and dichotomised ( 0 vs. $\geq 1$ GP visit). 'Low participant activation' was defined as having a lack of motivation, knowledge or confidence in taking an active role in one's own health care, indicated by a score of $\leq 55.1$ (one standard deviation below the mean) on the Patient Activation Measure (PAM) [19]. Psychological distress was measured using the Kessler Psychological Distress Scale (K10) [20], a validated instrument that measures anxiety and depression symptoms. A score of $\geq 22$ indicates 'high or very high psychological distress' based on scoring used in a number of Australian population health surveys [21]. 'Risky drinking' since the previous interview was defined as having a score of $\geq 16$ on the validated Alcohol Use Disorders Identification Test (AUDIT) [22], based on standard cut-offs. Data for this outcome were only collected at 3 and 6 month follow-ups. 'Daily tobacco smoking' referred to the four weeks prior to interview. 'Any cannabis use' and 'Any use of amphetamine-type stimulants' (ATS), such as amphetamines and ecstasy, referred to use in the four weeks prior to interview.

There were four welfare related outcomes. 'Unstable housing' referred to having an accommodation status at the time of interview that reflected primary, secondary or tertiary homelessness, taking into account the date of the interview, dependents and marital status. Social support was measured, using the Enriched Social Support Inventory (ESSI) [23] with a score of $\leq 18$ indicating 'low perceived social support' since the previous interview (based on standard cut-offs). 'Unemployment' was defined as not being in paid work for most of the time since the previous interview. 'Living in poverty' was assessed as having an income in the four weeks before the interview that was below the poverty line as defined by the published Australian standard [24], taking into account the date of the interview, dependents and marital status.

\subsubsection{Covariates}

Based on a review of the literature, we selected 35 baseline variables to serve as covariates in the analyses; all were dichotomised. An additional variable was adjusted for exposure to the Passports intervention. Socio-demographic covariates included sex, Indigenous status, education, and relationship status. Socio-economic covariates included housing stability, employment status, living in poverty, and outstanding debts to be settled after release. Criminal justice covariates included prior adult incarceration, prior juvenile detention, illegal income prior to incarceration, length of incarceration, drug-related index incarceration, and parole status on release. Substance use covariates included the following: risky drinking; risky tobacco, cannabis, methamphetamine or opioid (heroin and other opiates) use; history of sharing needles or other drug-injecting equipment; and sharing of needles or other drug-injecting equipment during index incarceration. 
Mental health covariates included lifetime history of self-harm and/or suicide attempt, central nervous system (CNS) medication use indicating mental disorder, psychological distress at baseline, and intellectual disability. Physical health covariates included testing positive for hepatitis $\mathrm{C}$ exposure, prior diagnosis of sexually transmitted infection, receiving a tattoo in prison, having one or more chronic illnesses, poor physical health, and low activation level. Social support covariates included visits in prison, perceived social support, separation from family as a child, and pre-and post-release transitional support from Queensland Corrective Services. A definition of each covariate is provided in Supplementary Table S1.

\subsection{Data Analysis}

First, we computed unadjusted odds ratios (ORs) for the association between the age category and each outcome. Next, we developed a multivariate logistic regression model for each outcome at each time point, adjusting for baseline covariates. While the covariates included were different for each outcome, they were the same across time points for each outcome. We did this by initially entering all covariates in each model and then, for each outcome, retaining only those that were significant at $p<0.10$ at one or more time points. The inclusion of a variable in the model required a minimum of $5 \%$ of each age group to be exposed to the outcome.

We assessed attrition by constructing a series of unadjusted logistic regression models, followed by multivariate logistic regression models to identify any interaction between age and other predictors of attrition. All analyses were conducted in Stata version 14.0 [25].

\section{Results}

\subsection{Descriptive Statistics}

Baseline interviews were conducted with 1325 participants. Of these, 144 were removed due to the baseline interview being conducted more than six weeks prior to release from index incarceration. This resulted in a sample of 1181 participants of whom $298(25.2 \%)$ were aged under 25 years at baseline. Follow-up fractions at 1, 3 and 6 month follow-ups for adolescents compared with their older peers were $60 \%$ vs. $68 \%\left(\chi^{2}[2,1181]=5.45\right.$, $p=0.02) ; 50 \%$ vs. $64 \%\left(\chi^{2}[2,1181]=17.62, p=<0.01\right)$; and $47 \%$ vs. $58 \%\left(\chi^{2}[2,1181]=12.06\right.$, $p=<0.01)$. Indigenous status (aOR $=1.99 ; 95 \%$ CI 1.13-3.52; $p=0.02)$, unstable housing $(\mathrm{aOR}=1.83 ; 95 \% \mathrm{CI} 1.10-3.03 ; p=0.02)$, prior juvenile detention $(\mathrm{aOR}=1.69 ; 95 \% \mathrm{CI}$ $1.05-2.73 ; p=0.03)$, receiving a tattoo in prison $(\mathrm{aOR}=1.99 ; 95 \% \mathrm{CI} 1.18-3.36 ; p=0.01)$, and being diagnosed with a chronic illness $(\mathrm{aOR}=0.55 ; 95 \% \mathrm{CI} 0.36-0.85 ; p=0.01)$ at baseline predicted loss to follow-up. Chronic illness was the only predictor of attrition found to have a significant interaction with age $(\mathrm{aOR}=2.65 ; 95 \% \mathrm{CI} 1.08-6.49 ; p=0.03)$.

\subsection{Participant Characteristics at Baseline}

Supplementary Table S2 displays all baseline characteristics considered for inclusion in regression analyses, according to age ( $<25$ years vs. $\geq 25$ years). Compared with their older peers, adolescents were significantly more likely to be Indigenous and less likely to be married or in a de facto relationship. Adolescents were less likely to have experienced previous adult incarceration; less likely to have ever shared injecting equipment; less likely to be taking a central nervous system (CNS) medication; less likely to have ever received a tattoo in prison; less likely to have any chronic diseases; less likely to have poor physical health; and less likely to have tested positive for hepatitis $C$ antibodies. They were also less likely to have completed ten years of schooling; more likely to have experienced juvenile detention; more likely to have had an illegal income prior to their current incarceration; more likely to be risky users of alcohol, cannabis and tobacco; more likely to have an intellectual disability; more likely to report low levels of activation; and less likely to report pre- and post-release reintegration support. Supplementary Table S3 provides details on all baseline variables selected for each reduced model. 


\subsection{Primary and Secondary Outcomes across the First Six Months Following Release}

At the 1 month follow-up, $71 \%$ of adolescents and $81 \%$ of adults were unemployed. One in six adults $(16 \%)$ and one in 14 adolescents $(7 \%)$ reported low levels of perceived social support. High psychological distress was reported by $18 \%$ of adolescents and $26 \%$ of adults. After three months, $57 \%$ of adolescents and $67 \%$ of adults were unemployed. Twice as many adolescents reported high risk/dependent drinking (18\% vs. 9\%). After six months, $15 \%$ of adolescents and $23 \%$ of adults reported high psychological distress, and use of amphetamine-type stimulants was reported by $12 \%$ of adolescents and $7 \%$ of adults.

Tables 1-3 display the prevalence of each outcome at each time point, and the unadjusted and adjusted odds ratios (aOR) for associations between age category and outcomes at 1,3 and 6 months post-release, respectively.

Table 1. Associations between age and key outcomes at 1 month follow-up.

\begin{tabular}{|c|c|c|c|c|c|c|c|}
\hline Outcome & $n$ & $\begin{array}{l}\text { Adults } \\
(n, \%)\end{array}$ & $\begin{array}{l}\text { Adolescents } \\
(n, \%)\end{array}$ & OR $(95 \% C I)$ & $p$ & aOR $(95 \% C I)$ & $p$ \\
\hline Unstable housing & 779 & $108(18.1)$ & $29(16.0)$ & $0.87(0.55-1.36)$ & 0.53 & $0.87(0.53-1.44)$ & 0.59 \\
\hline Unemployment & 781 & $486(81.0)$ & $129(71.3)$ & $0.58(0.40-0.85)$ & 0.01 & $0.31(0.15-0.63)$ & 0.001 \\
\hline Poverty & 595 & $336(70.9)$ & $81(66.9)$ & $0.83(0.54-1.28)$ & 0.40 & $0.56(0.27-1.16)$ & 0.12 \\
\hline Low perceived social support & 777 & $97(16.3)$ & $13(7.2)$ & $0.40(0.22-0.73)$ & 0.00 & $0.41(0.21-0.80)$ & 0.01 \\
\hline Low activation & 773 & 247 (41.7) & $95(52.5)$ & $1.54(1.10-2.16)$ & 0.01 & $1.55(0.91-2.63)$ & 0.11 \\
\hline High psychological distress & 775 & $154(25.9)$ & $33(18.3)$ & $0.64(0.42-0.98)$ & 0.04 & $0.50(0.25-0.99)$ & 0.045 \\
\hline High risk/dependent drinking & - & - & - & - & - & - & - \\
\hline Daily tobacco smoking & 607 & 408 (90.7) & $142(90.5)$ & $0.97(0.52-1.81)$ & 0.94 & $0.83(0.38-1.80)$ & 0.64 \\
\hline Cannabis use & 777 & $98(16.4)$ & $35(19.4)$ & $1.23(0.80-1.89)$ & 0.35 & $0.69(0.35-1.36)$ & 0.28 \\
\hline ATS drug use & 778 & $60(10.1)$ & $28(15.5)$ & $1.64(1.01-2.66)$ & 0.045 & $1.42(0.65-3.11)$ & 0.38 \\
\hline Unsafe sex & 509 & $54(15.0)$ & $26(17.3)$ & $1.18(0.71-1.98)$ & 0.52 & $1.08(0.49-2.43)$ & 0.84 \\
\hline No GP visit & 767 & $276(46.9)$ & $123(68.7)$ & $2.39(1.50-3.82)$ & 0.00 & $2.95(1.62-5.38)$ & 0.00 \\
\hline
\end{tabular}

Analyses were adjusted (a-OR) for a selection of the 35 covariates outlined in Section 2.3.3, with specific covariates for each analysis provided in Supplementary Table S3.

Table 2. Associations between age and key outcomes at 3 month follow-up.

\begin{tabular}{|c|c|c|c|c|c|c|c|}
\hline Outcomes & $n$ & $\begin{array}{l}\text { Adults } \\
(n, \%)\end{array}$ & $\begin{array}{c}\text { Adolescents } \\
(n, \%)\end{array}$ & OR $(95 \% C I)$ & $p$ & aOR $(95 \% \mathrm{CI})$ & $p$ \\
\hline Unstable housing & 710 & $103(18.4)$ & $21(14.0)$ & $0.72(0.43-1.20)$ & 0.21 & $0.79(0.45-1.38)$ & 0.41 \\
\hline Unemployment & 711 & $378(67.4)$ & $85(56.7)$ & $0.63(0.44-0.91)$ & 0.02 & $0.37(0.19-0.74)$ & 0.004 \\
\hline Poverty & 673 & $358(67.7)$ & $91(63.2)$ & $0.82(0.56-1.20)$ & 0.31 & $0.59(0.31-1.11)$ & 0.10 \\
\hline Low perceived social support & 709 & $99(17.7)$ & $21(14.1)$ & $0.76(0.46-1.27)$ & 0.30 & $0.68(0.38-1.22)$ & 0.20 \\
\hline Low activation & 711 & $254(45.3)$ & $79(52.7)$ & $1.34(0.94-1.93)$ & 0.11 & $1.33(0.73-2.42)$ & 0.35 \\
\hline High psychological distress & 710 & $128(22.9)$ & $24(16.0)$ & $0.64(0.40-1.04)$ & 0.07 & $0.76(0.36-1.60)$ & 0.47 \\
\hline High risk/dependent drinking & 696 & $51(9.3)$ & $27(18.4)$ & $2.20(1.32-3.65)$ & 0.00 & $1.69(0.70-4.11)$ & 0.24 \\
\hline Daily tobacco smoking & 528 & $365(89.7)$ & $107(88.4)$ & $0.88(0.46-1.67)$ & 0.70 & $0.91(0.42-2.00)$ & 0.82 \\
\hline Cannabis use & 708 & $99(17.7)$ & $30(20.1)$ & $1.17(0.74-1.85)$ & 0.50 & $1.75(0.82-3.74)$ & 0.15 \\
\hline ATS drug use & 710 & $50(8.9)$ & $15(10.0)$ & $1.13(0.62-2.08)$ & 0.69 & $2.32(0.77-6.97)$ & 0.13 \\
\hline Unsafe sex & 485 & $38(10.6)$ & $18(14.1)$ & $1.37(0.75-2.51)$ & 0.30 & $0.57(0.20-1.67)$ & 0.31 \\
\hline No GP visit & 704 & $251(45.2)$ & $99(66.4)$ & $2.65(1.70-4.14)$ & 0.00 & $2.05(1.04-4.07)$ & 0.04 \\
\hline
\end{tabular}

Analyses were adjusted (a-OR) for a selection of the 35 covariates outlined in Section 2.3.3, with specific covariates for each analysis provided in Supplementary Table S3. 
Table 3. Associations between age and key outcomes at 6-month follow-up.

\begin{tabular}{|c|c|c|c|c|c|c|c|}
\hline Outcomes & $n$ & $\begin{array}{l}\text { Adults } \\
(n, \%)\end{array}$ & $\begin{array}{c}\text { Adolescents } \\
(n, \%)\end{array}$ & OR $(95 \% \mathrm{CI})$ & $p$ & aOR $(95 \% \mathrm{CI})$ & $p$ \\
\hline Unstable housing & 651 & $98(19.1)$ & $22(15.8)$ & $0.79(0.48-1.32)$ & 0.37 & $0.88(0.50-1.55)$ & 0.66 \\
\hline Unemployment & 654 & $331(64.3)$ & $83(59.7)$ & $0.82(0.56-1.21)$ & 0.32 & $0.56(0.28-1.12)$ & 0.10 \\
\hline Poverty & 625 & $285(57.9)$ & $83(62.4)$ & $1.20(0.81-1.79)$ & 0.35 & $0.74(0.38-1.42)$ & 0.36 \\
\hline Low perceived social support & 650 & $84(16.4)$ & $22(15.8)$ & $0.96(0.57-1.59)$ & 0.86 & $1.09(0.61-1.96)$ & 0.76 \\
\hline Low activation & 650 & $200(39.1)$ & $66(47.8)$ & $1.43(0.98-2.09)$ & 0.06 & $1.02(0.54-1.94)$ & 0.95 \\
\hline High psychological distress & 648 & $115(22.5)$ & $21(15.3)$ & $0.62(0.37-1.04)$ & 0.07 & $0.58(0.24-1.39)$ & 0.22 \\
\hline High risk/dependent drinking & 638 & $56(11.2)$ & $29(21.3)$ & $2.16(1.32-3.54)$ & 0.00 & $2.43(0.99-5.95)$ & 0.052 \\
\hline Daily tobacco smoking & 498 & $335(87.9)$ & $104(88.9)$ & $1.10(0.57-2.11)$ & 0.78 & $1.00(0.43-2.31)$ & 1.00 \\
\hline Cannabis use & 650 & $84(16.4)$ & $33(23.7)$ & $1.58(1.00-2.50)$ & 0.05 & $1.14(0.52-2.52)$ & 0.74 \\
\hline ATS drug use & 650 & $37(7.2)$ & $16(11.5)$ & $1.67(0.90-3.09)$ & 0.11 & $3.42(1.29-9.09)$ & 0.014 \\
\hline Unsafe sex & 461 & $37(10.8)$ & $13(11.0)$ & $1.02(0.52-2.00)$ & 0.95 & $0.49(0.15-1.58)$ & 0.23 \\
\hline No GP visit & 643 & $205(40.5)$ & $87(63.5)$ & $2.73(1.75-4.26)$ & 0.00 & $1.86(0.94-3.69)$ & 0.08 \\
\hline
\end{tabular}

Analyses were adjusted (a-OR) for a selection of the 35 covariates outlined in Section 2.3.3, with specific covariates for each analysis provided in Supplementary Table S3.

\subsection{Primary Outcomes (Health)}

After one month, a lower proportion of adolescents reported high psychological distress. In an adjusted model, adolescents were half as likely as their older peers to report high levels of psychological distress ( $\mathrm{aOR}=0.50 ; 95 \% \mathrm{CI} 0.25-0.99 ; p=0.001)$. A larger proportion of adults also reported having visited their GP at least once. After adjusting for covariates, adults were almost three times more likely than adolescents to have visited a GP since release $(\mathrm{aOR}=2.95 ; 95 \%$ CI 1.62-5.38; $p=<001)$. Compared to their older counterparts, a significantly larger proportion of adolescents reported having low activation levels $(\mathrm{OR}=1.54 ; 95 \% \mathrm{CI} 1.10-2.16 ; p=0.01)$ and engaging in ATS drug use $(\mathrm{OR}=1.64 ; 95 \% \mathrm{CI} 1.01-2.66 ; p=0.045)$. However, these associations were attenuated after adjusting for covariates.

After three months, a larger proportion of adolescents reported high risk/dependent drinking, compared to their older peers (OR $=2.20 ; 95 \%$ CI 1.32-3.65; $p<0.001)$. However, this association was attenuated after adjusting for covariates. Further, a larger proportion of adults reported having visited their GP at least once: adults were twice as likely as adolescents to have visited a GP $(\mathrm{aOR}=2.05 ; 95 \%$ CI 1.04-4.07; $p=<.001)$.

After six months, an adjusted model demonstrated that adolescents were more than three times as likely to have used amphetamine-type stimulants $(\mathrm{aOR}=3.42 ; 95 \% \mathrm{CI}$ $1.29-9.09 ; p=0.014$ ) than their older peers. A larger proportion of adolescents also reported high risk/dependent drinking, compared to adults (OR $=2.16$; 95\% CI 1.32-3.54; $p<0.001$ ). After adjusting for covariates, the point estimates for high-risk drinking suggested a higher prevalence in adolescents at the 6 month follow-up, but $95 \%$ CIs spanned unity ( $\mathrm{aOR}=2.43$; $95 \%$ CI $0.99-5.95 ; p=0.052)$. A larger proportion of adults reported having visited their GP at least once $(\mathrm{OR}=2.73 ; 95 \% \mathrm{CI} 1.75-4.26 ; p<0.001)$. However, this association was attenuated after adjusting for covariates.

\subsection{Secondary Outcomes (Welfare)}

After one month, a significantly larger proportion of adults were unemployed and reported having low levels of social support. After adjusting for covariates, adolescents were three times less likely to be unemployed ( $\mathrm{aOR}=0.31 ; 95 \% \mathrm{CI} 0.15-0.63 ; p=0.001)$, and less likely to report low perceived social support $(\mathrm{aOR}=0.41 ; 95 \% \mathrm{CI} 0.21-0.80 ; p=0.01$ ) than their older peers.

After three months, a larger proportion of adults were unemployed. After adjusting for covariates, adults were still approximately three times more likely than adolescents to be unemployed $(\mathrm{aOR}=0.37 ; 95 \% \mathrm{CI} 0.19-0.74 ; p=<.001)$. After six months, there were no significant differences between adolescents and adults regarding welfare outcomes. 
Figure 1 displays all outcomes that were significantly different between adolescents and adults over time, after adjusting for covariates.

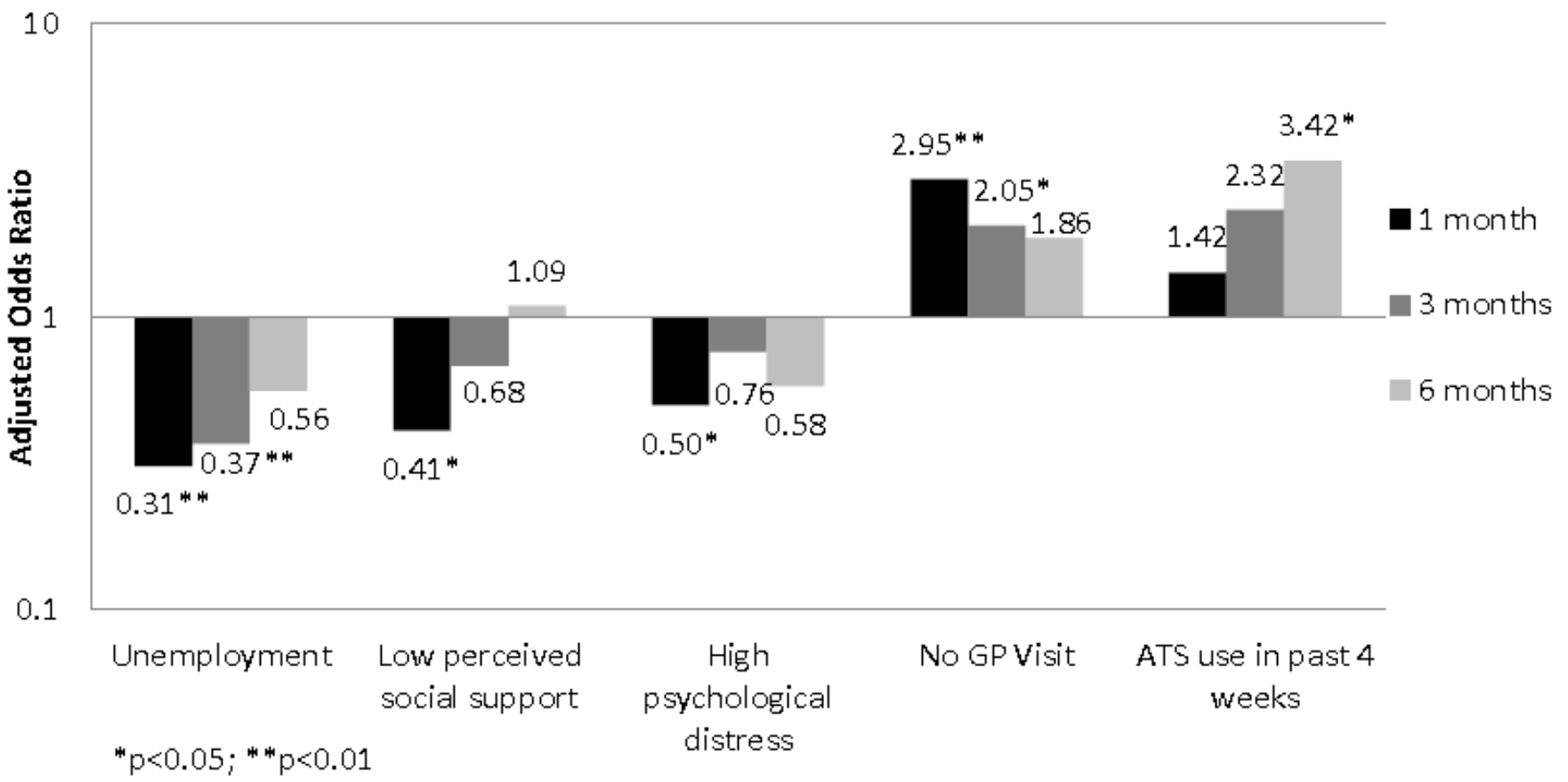

Figure 1. Adjusted odds ratios of post-release outcomes for adolescents versus adults (reference category).

\section{Discussion}

The aim of this study was to examine the health and welfare outcomes reported by a representative sample of adolescents during the first six months following release from prisons in Queensland, Australia, compared to their older peers. We found that adolescents reported a markedly different trajectory than adults during their first six months following release, as indicated by a considerably different risk profile. Adolescents were less likely than their older peers to have visited a GP, with only $36.5 \%$ doing so during the first six months. Adolescents were also more than three times as likely to have used amphetaminetype stimulants, with one in nine $(11.5 \%)$ doing so within the first six months. However, adolescents fared better than older participants on securing employment $(43.3 \%$ vs. $32.6 \%$ after three months, respectively) and were more likely to reported having an adequate level of social support ( $92.8 \%$ vs. $83.7 \%$ after one month). Finally, fewer adolescents reported experiencing high levels of psychological distress ( $18.3 \%$ vs. $25.9 \%$ after one month).

Importantly, the observed associations between age category and these health and welfare outcomes remained significant after adjusting for a wide range of covariates. It is notable that the variables for which adolescents consistently reported poorer outcomes (e.g., GP visits, risky ATS use) were health-related, whereas the variables for which they reported more positive outcomes (e.g., perceived social support, psychological distress, and employment) were psychosocial or welfare-related. One interpretation of these findings is that adolescents released from prison have comparatively strong social capital but are more likely to engage in health-compromising behaviours and less likely to access preventive healthcare. To the extent that this is the case, efforts to improve health outcomes for adolescents released from prison may be enhanced by investing in social determinants of health, such as employment and prosocial support networks. Furthermore, the limited available resources should be directed disproportionately toward age-appropriate interventions to improve health service access, including drug and alcohol treatment services, in the transition period immediately prior to and following release. Our findings also indicate that adolescents seemed to fare more positively than their older peers immediately after release, but this picture became progressively poorer over the first six months. Post-release 
support programs, to the extent that they are available, typically target welfare issues and not health issues, and tend to be limited to the first few months after release. Our findings suggest that outcomes for adolescents released from prison would be improved by (a) increasing the focus on health outcomes in transitional care, and (b) maintaining this care for a longer duration.

\section{Strengths and Limitations}

Our study contained several strengths. First, by conducting multiple follow-up assessments within a short period of time, we were able to obtain a more nuanced picture of the temporal patterns of multiple psychosocial and behavioural risk factors following release from prison. Second, our sample was large and broadly representative of all people being released from prison in Queensland across the study duration with a range of demographic and criminogenic variables [18], maximising the generalisability of our findings. Third, ours is one of the largest prospective studies of people released from prison globally and, to our knowledge, the first to compare health and welfare outcomes for adolescents with their older peers after release from prison. Fourth, we collected rich baseline data to permit extensive adjustment for covariates. Fifth, we used validated instruments to assess most key measures. Finally, we maintained quite good participant retention in light of the challenges associated with retaining this population in longitudinal studies [26].

Our findings should be viewed in light of some potential limitations. First, we assessed all outcomes_-including substance use-via self-report. However, participants are likely to under-report rather than over-report drug-related behaviours [27], so it is likely that our estimates were conservative, and we have previously demonstrated that self-reported healthcare contact in this population is reliable [28]. Second, to the extent that outcomes are associated with loss to follow-up, the study may have experienced biased attrition. Similarly, as a larger proportion of adolescents than older participants were lost to followup, this bias may have resulted in attenuation of age-related differences, where adolescents had a higher incidence of an adverse outcome. However, results of our attrition analysis suggest that age played a very limited role in attrition. Finally, although our findings may be reasonably extrapolated to other Australian jurisdictions, it remains unclear whether similar age-related differences exist among incarcerated individuals in other countries. As such, replication in other settings is recommended.

\section{Implications}

Our findings indicate that approximately one in ten adolescents reported engaging in risky drinking and/or using amphetamine-type stimulants at each of the follow-up points. These proportions are high and are almost certainly an underestimate of the true picture. Previous research has identified adolescence as a period in which young people commonly engage in increased levels of behaviours characterised by sensation-seeking and risk-taking [3]. Health risk behaviours such as these, along with the early disengagement from education common in our sample, are associated with poor health outcomes and recidivism [4].

Additionally, adolescents were markedly less likely than their older peers to have visited a GP during the first three months after release from prison. The implications of early primary care physician contact following release from prison in shaping subsequent health service utilisation are considerable. In a 2015 paper based on this cohort, Young and colleagues [29] demonstrated that contact with a primary care physician within one month of release was associated with increased health service utilisation during the critical community transition period. Specifically, early GP contact was positively associated with subsequent hospital, mental health service, and substance use treatment contact over six months of follow-up. Our findings suggest that, for adolescents in our cohort, incarceration may have represented a missed opportunity for effective substance-use treatment and increased engagement with health services. 
Adolescents in our study reported lower levels of unemployment than adults, yet the rates of unemployment in both age groups were still high $(\geq 56 \%$ for both groups at all three follow-up points). Whilst the relationship between employment and subsequent contact with the criminal justice system is complex, unemployment has been linked to both poor health outcomes and subsequent reincarceration [5-7]. Both adolescents and adults released from incarceration may benefit from sustained employment-related supports, including affordable vocational education, job placement, on-the-job training, and case management for a predefined period of time [8].

In many countries, including Australia, adolescents account for approximately onefifth of all incarcerated people [5]. However, as adolescents typically serve shorter sentences, they account for approximately $25 \%$ of all prison releases [30]. In light of this, the ability to gain access to these adolescents in order to provide additional support appears to be a rapidly closing window of opportunity for tertiary prevention [13]. Further research is required to understand the extent to which this opportunity is being seized, and what barriers may exist to enhancing health-focused, age-appropriate, and sustained re-entry support for adolescents transitioning from prison to the community. Given the challenges of recruiting and retaining justice-involved adolescents in longitudinal studies, multisectoral data linkage will be one critical method for documenting the health, welfare and justice outcomes for this population, in both descriptive studies and the evaluation of age-appropriate responses [9].

\section{Conclusions}

Our study adds to a growing body of literature examining the health and social outcomes of adolescents transitioning from prison to the community [9,15]. Significant differences between adolescents and older participants were present on several measures, both at baseline and after release. Our findings highlight the pressing need for improved, integrated, and age-specific support for adolescents during the critical transition period from prison to the community, including strategies to discourage risky substance use, capitalise on social support networks, and promote early primary care contact. Given the large and growing number of vulnerable adolescents who experience incarceration globally, and emerging evidence of poor health outcomes for these adolescents, investment in evidence-based efforts to improve their health and welfare outcomes has the potential to both break cycles of re-incarceration and contribute to reducing health inequalities at the population level.

Supplementary Materials: The following are available online at https:/ /www.mdpi.com/article/ 10.3390/adolescents1020014/s1, Table S1. Covariate definitions; Table S2. Baseline characteristics according to age $(\mathrm{N}=1181)$; Table S3: Baseline covariates in reduced adjusted regression models.

Author Contributions: All authors contributed to the conceptual design of the study and conceived the study aims. D.d.A. was the primary data analyst and drafted the methods and results sections. R.B. drafted the abstract, introduction and discussion sections. S.A.K. directed data analysis and is the principal investigator for the Passports study; he designed the study protocol and managed data collection. All authors have read and agreed to the published version of the manuscript.

Funding: Funding for this study was supported by Australian National Health and Medical Research Council (NHMRC) Strategic Award GNT409966 and Australian Research Council (ARC) Discovery Project DP140102333. SK is supported by an NHMRC Senior Research Fellowship (GNT1078168). Funding bodies had no role in the study design; collection, analysis, and interpretation of the data; writing the report; or decision to submit the report for publication.

Institutional Review Board Statement: The study was conducted according to the guidelines of the Declaration of Helsinki, and approved by the University of Queensland Behavioural and Social Sciences Ethical Review Committee (Project \#2007000607), Queensland Corrective Services Research Committee, and the Australian Institute of Health and Welfare (AIHW) Ethics Committee.

Informed Consent Statement: Informed consent was obtained from all participants in the study. 
Data Availability Statement: The datasets generated and/or analysed during the current study are not publicly available due to the sensitive nature of information collected but are available from the corresponding author upon reasonable request.

Acknowledgments: The authors wish to thank Queensland Corrective Services for assistance with data collection and the Passports study participants for sharing their experiences. The views expressed herein are solely those of the authors and in no way reflect the views or policies of Queensland Corrective Services.

Conflicts of Interest: The authors report no perceived or actual conflict of interest associated with the conduct of, or dissemination of findings from, this study.

\section{References}

1. Sawyer, S.; Azzopardi, P.; Wickremarathne, D.; Patton, G. The age of adolescence. Lancet Child Adolesc. Health. 2018, 2, 223-228. [CrossRef]

2. UN, Division for Social Policy and Development. World Youth Report 2007; United Nations, Department of Economic and Social Affairs: New York, NY, USA, 2007. Available online: http://www.un.org/esa/socdev/unyin/documents/wyr07_introduction. pdf (accessed on 10 May 2021).

3. Kinner, S.A.; Degenhardt, L.; Coffey, C.; Sawyer, S.; Hearps, S.; Patton, G. Complex health needs in the youth justice system: A survey of community-based and custodial offenders. J. Adolesc. Health 2014, 54, 521-526. [CrossRef] [PubMed]

4. Pyle, N.; Flower, A.; Fall, A.M.; Williams, J. Individual-level risk factors of incarcerated youth. Remedial Spec. Educ. 2016, 37, 172-186. [CrossRef]

5. ABS. Prisoners in Australia 2016 (4517.0 2016); Australian Bureau of Statistics: Canberra, Australia, 2016.

6. Van Dooren, K.; Kinner, S.A.; Butler, T. Young prisoners: An important group for health research? J. Correct. Health Care 2010, 16, 322-327. [CrossRef] [PubMed]

7. Borschmann, R.; Janca, E.; Carter, A.; Willoughby, M.; Hughes, N.; Snow, K.; Stockings, E.; Hill, N.T.M.; Hocking, J.; Love, A.; et al The health of adolescents in detention: A global scoping review. Lancet Public Health 2020, 5, e114-e126. [CrossRef]

8. Kinner, S.A.; Jenkinson, R.; Gouillou, M.; Milloy, M.-J. High-risk drug-use practices among a large sample of Australian prisoners. Drug Alcohol Depend. 2012, 126, 156-160. [CrossRef] [PubMed]

9. Van Dooren, K.; Richards, A.; Lennox, N.; Kinner, S. Complex health-related needs among young, soon-to-be-released prisoners. Health Justice 2013, 1, 1-8. [CrossRef]

10. Binswanger, I.A.; Stern, M.F.; Deyo, R.A.; Heagerty, P.J.; Cheadle, A.; Elmore, J.G.; Koepsell, T.D. Release from prison-A high risk of death for former inmates. N. Engl. J. Med. 2007, 356, 157-165. [CrossRef]

11. Hammett, T.M.; Roberts, C.; Kennedy, S. Health-related issues in prisoner reentry. Crime Delinq. 2001, 47, 390-409. [CrossRef]

12. Mallik-Kane, K.; Visher, C.A. Health and Prisoner Reentry: How Physical, Mental, and Substance Abuse Conditions Shape the Process of Reintegration; Urban Institute Justice Policy Center: Washington, DC, USA, 2008.

13. Kinner, S.A.; Snow, K.; Wirtz, A.L.; Altice, F.L.; Beyrer, C.; Dolan, K. Age-specific global prevalence of Hepatitis B, Hepatitis C, HIV, and Tuberculosis among incarcerated people: A systematic review. J. Adolesc. Health 2018, 62, S18-S26. [CrossRef]

14. Van Dooren, K.; Kinner, S.A.; Hellard, M. A comparison of risk factors for hepatitis C among young and older adult prisoners. J. Correct. Health Care 2014, 20, 280-291. [CrossRef] [PubMed]

15. Van Dooren, K.; Kinner, S.A.; Forsyth, S. Risk of death for young ex-prisoners in the year following release from adult prison. Aust. N. Z. J. Public Health 2013, 37, 377-382. [CrossRef]

16. Kinner, S.A.; Dooren Kv Boyle, F.M.; Longo, M.; Lennox, N. Development of an intervention to increase health service utilisation in ex-prisoners. Health Justice 2014, 2, 4. [CrossRef]

17. Kinner, S.A.; Lennox, N.; Alati, R.; Boyle, F.; Longo, M.; Spittal, M.; Williams, G.M. Low-intensity service brokerage increases contact with health care in recently released prisoners: A single-blinded, multi-site randomised controlled trial. J. Epidemiol. Community Health 2015, 70, 683-688.

18. Kinner, S.A.; Lennox, N.; Williams, G.M.; Carroll, M.; Quinn, B.; Boyle, F.M.; Alati, R. Randomised controlled trial of a service brokerage intervention for ex-prisoners in Australia. Contemp. Clin. Trials 2013, 36, 198-206. [CrossRef]

19. Hibbard, J.H.; Stockard, J.; Mahoney, E.R.; Tusler, M. Development of the Patient Activation Measure (PAM): Conceptualizing and Measuring Activation in Patients and Consumers. Health Serv. Res. 2004, 39, 1005-1026. [CrossRef]

20. Kessler, R.C.; Andrews, G.; Colpe, L.J.; Hiripi, E.; Mroczek, D.K.; Normand, S.-L.T.; Walters, E.E.; Zaslavsky, A.M. Short screening scales to monitor population prevalences and trends in non-specific psychological distress. Psychol. Med. 2002, 32, 959-976. [CrossRef] [PubMed]

21. DHS. Victorian Population Health Surveys, 2001-2007; Department of Human Services, State Government of Victoria: Warrnambool, Australia, 2008. Available online: https:/ /hns.dhs.vic.gov.au/3netapps/vhisspublicsite/ReportParameter.aspx?ReportID=56 \&TopicID=1\&SubtopicID=17 (accessed on 10 May 2021).

22. Babor, T.F.; Higgins-Biddle, J.; Saunders, J.B.; Monteiro, M.G. AUDIT: The Alcohol Use Disorders Identification Test, Guidelines for Use in Primary Care, 2nd ed.; World Health Organisation (WHO): Geneva, Switzerland, 2001. 
23. Mitchell, P.H.; Powell, L.; Blumenthal, J.; Norten, J.; Ironson, G.; Pitula, C.R.; Froelicher, E.S.; Czajkowski, S.; Youngblood, M.; Huber, M.; et al. A short social support measure for patients recovering from myocardial infarction: The ENRICHD Social Support Inventory. J. Cardiopulm. Rehabil. 2003, 23, 398-403. [CrossRef] [PubMed]

24. MIAESR. Poverty Lines; Melbourne Institute of Applied Economic and Social Research, University of Melbourne: Carlton, Australia, 2014. Available online: http://melbourneinstitute.com/miaesr/publications/indicators/poverty-lines-australia.html (accessed on 10 May 2021).

25. Stata. Stata Release 15.0, 15th ed.; Stata Corporation: College Station, TX, USA, 2017.

26. David, M.C.; Alati, R.; Ware, R.S.; Kinner, S.A. Attrition in a longitudinal study with hard-to-reach participants was reduced by ongoing contact. J. Clin. Epidemiol. 2013, 66, 575-581. [CrossRef]

27. McGregor, K.; Mikkai, T. Self-Reported Drug Use: How Prevalent Is Under-Reporting? (Trends and Issues); Australian Institute of Criminology: Canberra, Australia, 2003.

28. Carroll, M.; Sutherland, G.; Kemp-Casey, A.; Kinner, S.A. Agreement between self-reported healthcare service use and administrative records in a longitudinal study of adults recently released from prison. Health Justice 2016, 4, 11. [CrossRef] [PubMed]

29. Young, J.T.; Arnold-Reed, D.; Preen, D.; Bulsara, M.; Lennox, N.; Kinner, S.A. Early primary care physician contact and health service utilisation in a large sample of recently released ex-prisoners in Australia: Prospective cohort study. BMJ Open 2015, 5, e008021. [CrossRef] [PubMed]

30. Avery, A.; Kinner, S.A. A robust estimate of the number and characteristics of persons released from prison in Australia. Aust. N. Z. J. Public Health 2015, 39, 315-318. [CrossRef] [PubMed] 